\title{
Ambulation in patients with myelomeningocele: a study of 1500 patients
}

\author{
I Díaz Llopis MD, M Bea Muñoz MD, E Martinez Agulló MD, A López Martinez MD, \\ V García Aymerich MD, JV Forner Valero MD
}

Department of Rehabilitation, La Fe Hospital, Valencia, Spain.

Data from 1500 patients affected by spina bifida have been collected in a multicentre study in Spain from 1986 to 1988. This paper is concerned with a part of the data, specifically regarding the walking of patients and certain factors that influence the prognosis for ambulation.

The neurological level of lesion most commonly present was lumbosacral $(65.6 \%)$. Hydrocephalus was frequent (62\% of the sample), and has significant implications regarding prognosis for walking.

Hip dislocation $(32 \%)$ and scoliosis $(22.9 \%)$ were orthopaedic problems noted in our sample. Pressure sores appeared in $31.7 \%$ of the patients.

The onset of walking ability has been studied; $15 \%$ of the sample started walking at an age older than 5 years.

Finally, different modalities of ambulation are described according to the use of ancillary devices, and in independence in activities of daily living.

Keywords: ambulation; myelomeningocele; spina bifida.

\section{Introduction}

A few years ago, patients with myelomeningocele were condemned to a short and distressing existence, but, nowadays, with medical advances in prophylaxis, and the treatment of neonatal meningitis and hydrocephalus, their life has been prolonged. In the next few years these patients, now almost exclusively children, will reach adulthood.

This new situation requires us to change their medical management, treating new and specific problems, and making every effort to improve their quality of life.

From the medical point of view, this quality of life depends to a certain extent on four features: locomotion; level of intelligence; urological problems (including sphincter incontinence); and genitosexual aspects. The problems concerning locomotion are the subject of our study.

It is our opinion that compared to other reports in the literature, the importance of this study relates to the large number of patients with myelomeningocele that we have been able to study. Determining factors for walking ability are: neurological level; hydrocephalus; orthopaedic problems; pressure ulcers; and others (eg obesity, family conditions, etc). The management of these problems has allowed ambulation for a great number of patients.

\section{Material and methods}

The data of this work come from a multicentre study begun in 1986 and concluded in 1988 , covering the whole of Spain, under the direction of Dr E Martinez Agulló and Dr V Alberola Cuñat. ${ }^{1}$

Private and public associations' records (Table I), and hospitals' and doctors' files and records were used to obtain the cases: a total number of 1770 patients was obtained, a questionnaire was prepared, and 1500 patients were interviewed (Table II) by appropriately trained doctors, nurses, psychologists, and social workers.

The medical and psychosocial aspects of myelomeningocele were included in the questionnaire, only a part of which has been used in the preparation of this paper, to obtain relevant information about the level of injury, hydrocephalus, orthopaedic complications, pressure sores, and onset and type of ambulation achieved. 
Table I Private and public associations used to obtain a list of patients with myelomeningocele

Hospital files

List fron the Dirección Nacional del INSERSO

Directories from the Direcciones Generales de Bienestar de las Comunidades Autónomas

Spina Bifida Associations from Algeciras, Córdoba, Granada, Jaen, Málaga, Zaragoza, Asturias, Canarias, Cantabria, Castilla-León, Catalunya, Madrid, Murcia, Alava, Gipuzcoa, Vizcaya, Alicante, Valencia

Table II Number of patients identified and interviewed according to the community to which they belong. Number of patients identified $=1770$, number of patients interviewed $=1500$

\begin{tabular}{lrrr}
\hline Community & Identified & Interviewed & $\begin{array}{c}\text { Community } \\
\text { population }\end{array}$ \\
\hline Andalucía & 149 & 136 & $6,558,542$ \\
Aragón & 75 & 44 & $1,196,952$ \\
Asturios & 25 & 22 & $1,129,556$ \\
Baleares & 39 & 39 & 655,909 \\
Canarias & 49 & 48 & $1,367,646$ \\
Cantabria & 23 & 22 & 513,115 \\
Castilla-La Mancha & 54 & 48 & $1,648,586$ \\
Catalunya & 294 & 294 & $5,956,414$ \\
Extremadura & 12 & 12 & $1,065,168$ \\
Galicia & 84 & 51 & $2,811,922$ \\
La Rioja & 11 & 3 & 254,349 \\
Madrid & 299 & 281 & $4,686,895$ \\
Murcia & 93 & 93 & 955,487 \\
Navarra & 6 & 5 & 509,002 \\
Pais Vasco & 155 & 110 & $2,141,809$ \\
Pais Valenciano & 402 & 292 & $3,646,778$ \\
\hline
\end{tabular}

Fifty-three percent of the sampled population were male, and $47 \%$ female. The population's age was distributed as follows: $8 \%$ were younger than 2 years of age; $14.2 \%$ were between $2-5$ years; $24.9 \%$ between $6-10$ years; $25.1 \%$ between $11-15$ years; $13 \%$ between $16-20$ years; $8.9 \%$ between 21-30 years; and 5\% were older than 31 years. We received no answer concerning age in $0.9 \%$ of the patients.

\section{Results}

The lumbosacral level of lesion (L3-S2) was the most commonly found in $65.6 \%$ (984 patients) of the sample, followed by the sacral level (S3-S5) with $18.1 \%$ (271 patients) (Fig 1).

Hydrocephalus appeared in 930 patients (62\% of the sample) and of those patients, $779(83.8 \%)$ were operated on, having a shunt. In this group, the following complica-

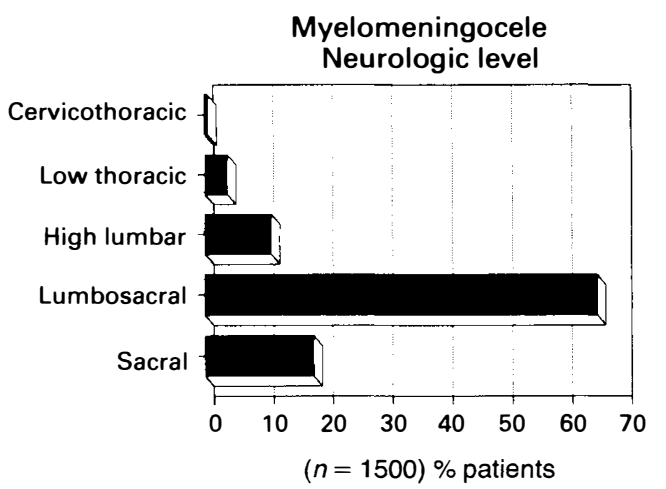

Figure 1 Neurological level in patients with myelomeningocele.

tions were found: infection of the shunt in 118 cases $(15.2 \%)$, obstruction of the system in 242 patients $(31.1 \%)$, and in 98 cases $(12.6 \%)$ the derivative system became disconnected.

The main spinal orthopaedic abnormality 
was scoliosis in 343 patients $(22.9 \%$ of the sample), with only $4.5 \%$ patients suffering from kyphosis. Hip dislocation occurred in $32 \%$ of the sample (480 patients). Pressure sores were also a common problem, occurring in 475 patients $(31.7 \%)$.

Walking ability was not achieved by $31.1 \%$ of the sample at the time of the study. Three hundred and four patients $(20.3 \%)$ started walking before their second year of life, and $453(30.2 \%)$ between the second and fourth year. Two point one percent of the sample were able to walk between their ninth and twelfth year (Fig 2).

Regarding assistive devices and aids for ambulation, 533 patients $(35.5 \%)$ were able to walk without such devices; 255 patients walked using crutches and orthosis; 102 used crutches only, and 230 orthosis only. Wheelchair use was required in $330,(22 \%)$ of the patients who were studied, for some or all of personal mobility (Fig 3).

\section{Discussion}

Gender predominance had not been stated clearly in the literature. Laurence ${ }^{2}$ found in a series of 407 patients a predominance of female $(57 \%)$. Another series ${ }^{3,4}$ shows a predominance of male patients, like ours $(52.9 \%)$.

Given our data, and comparing them with described predictors of ambulation, the following aspects require consideration:-

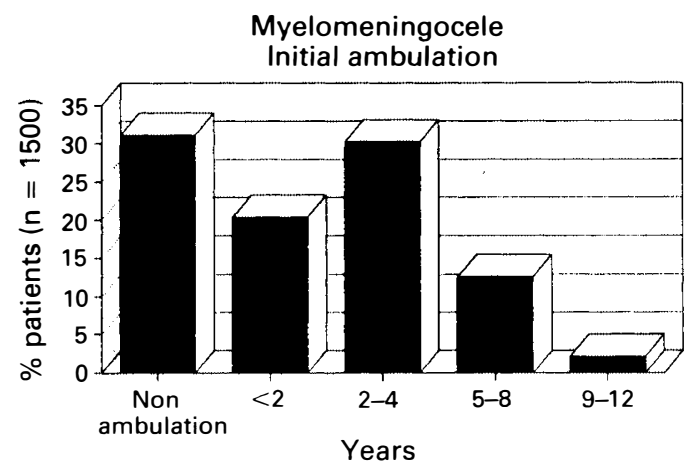

Figure 2 Age at which some kind of ambulation was achieved. In the first group figure those patients who were not able to walk when the sampling was made.

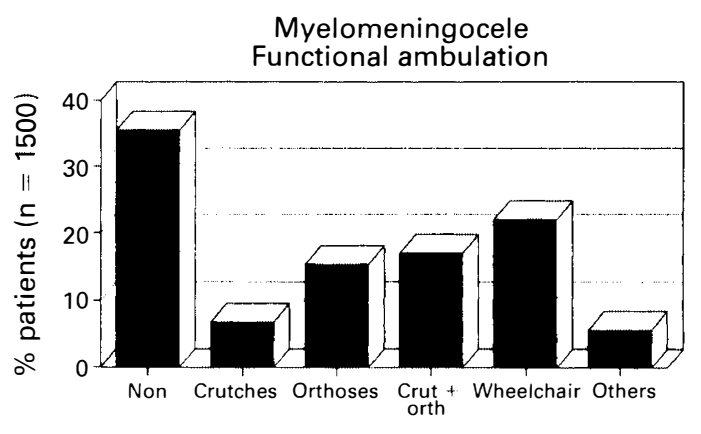

No answer: $5.2 \%$

Figure 3 Functional types of ambulation according to the different kinds of support received. Included are those patients who transfer themselves on a wheelchair and those who cannot walk.

Level of lesion: according to other published work the level of the lesion is the main predictor of ambulation, ${ }^{3-9}$ there being a high degree of correlation between lesion level and ambulatory ability. Lumbosacral lesions are the commonest in most series $^{3,4,9,10}$ and accounted for $65.6 \%$ of patients in our study. These patients have at least some ambulatory potential either using unparalysed muscles alone or with the help of assistive devices.

Hydrocephalus: this factor will affect the chances of survival and the future level of intelligence. Obstruction or infection of the shunt can suddenly impair the patient's quality of life. Comparing with previous series $^{11-13}$ a low percentage has been obtained $(62 \%$ vs $70 \%-90 \%)$. Probably, patients severely affected by hydrocephalus have died during their first years of life, and have not been included in the sample, justifying this difference in percentage.

Patients with shunts $(83.8 \%)$, or their parents have to be informed of the dangers of shunt dysfunction. This warning may prevent long periods in bed, avoiding musculoskeletal deformities and walking problems. Adequate management of hydrocephalus will also improve intelligence.

Orthopaedic problems: the most frequent spinal deformity, as previously reported, has been scoliosis. ${ }^{14,15}$ Shurtelf ${ }^{16}$ found kyphosis more frequent in young children 
because it is a congenital deformity, and scoliosis in older ones (acquired deformity). The relatively high percentage of kyphosis in our study can be related to the large number of young children.

In agreement with other authors, ${ }^{14,16}$ the most frequent lower limb deformity, excluding the feet, has been hip dislocation.

The development of one of these orthopaedic problems, in those with lower lumbar and sacral lesions can threaten the ambulatory ability in some patients. ${ }^{3}$

Pressure sores: these can give rise to a delay or loss of walking ability. Previous works relating inability and pressure sores have not been found.

A high percentage of patients $(35.5 \%)$ able to walk without help (community ambulators) has been obtained; $22 \%$ required to use a wheelchair. The remainder $(39.5 \%)$ use crutches, orthoses or both. This last group would include community ambulators and household ambulators, according to Hoffer's classification. ${ }^{6}$

According to Cuxart ${ }^{5}$ the onset of ambulation takes place frequently between $24-36$ months of age. However, patients in our sample achieved this walking ability some time later. Two point one percent of patients started to walk at 9 years of age. For this reason, these patients have to be well taken care of in order to achieve any degree of ambulation. We should not forget that there are also ambulating patients who lose their ability to walk.

\section{Conclusion}

Neurological level is the most important predictive factor concerning ambulatory capacity. The common site of myelomeningoceles, in the lumbosacral region, is not a factor in impairing ambulatory prognosis. This puts much emphasis on preventing complications such as hydrocephalus, musculoskeletal problems, and pressure sores, to maintain ambulation and permit a good quality of life.

Patients who have myelomeningocele often have a delay in achieving ambulation, but through rehabilitation of their spared muscles we have to ensure that they obtain the most useful kind of ambulation possible.

\section{References}

1 Martinez-Agulló E, Alberola V (1988) Multicentre study of patients with myelomeningocele. IVth National Congress on Spina Bifida. Diputación Provincial de Valencia: 19-93.

2 Laurence KM (1964) The natural history of spina bifida cystica. Detailed analysis of 407 cases. Arch Dis Child 39: 41-57.

3 Asher MD (1983) Factors affecting the ambulatory status of patients with spina bifida cystica. J Bone Joint Surg 65(3): 350-6.

4 Findley TW, Agre JC, Habeck RV, Schmalz R, Birkeback RR, McNally MC (1987) Ambulation in the adolescent with myelomeningocele I: Early childhood predictors. Arch Phys Med Rehabil 67: 518-522.

5 Cuxart A (1982) Prospective study of walking ability in patients with myelomeningocele. Communication in the 1st National Congress on Spina Bifida. Barcelona, Spain.

6 Hoffer M, Feiwell E, Perry R, Bonnett C (1973) Functional ambulation in patients with myelomeningocele. J Bone Joint Surg 25(1): 137-11.

7 Rose GK, Sankarankutty M, Stallard J (1983) A clinical review of the orthotic treatment of myelomeningocele patients. J Bone Joint Surg 65B: 242-246.

8 Soria L, Sarmiento V, Ramos V, Toledo M (1991) Gait analysis in myelomeningocele. Condition of the hips and other prognostic associated factors. A clinical and bibliographics review. Rehabilitación 25(4): 217-221.

9 Stillwell A, Menelans M (1983) Walking ability in mature patients with spina bifida. J Pediatr Orthop 3(2): 184-90.

10 Matson DD (1969) Neurosurgery of Infancy and Childhood. Charles C Tomas, Springfield, Illinois.

11 Badell-Ribera MD (1964) Spina bifida with myelomeningocele: evaluation of rehabilitation potencial. Arch Phys Med Rehabil Sept: 443-90.

12 Gans BM (1988) Rehabilitation of the pediatric patient. In: Delisa JA, editor. Rehabilitation Medicine. Principles and Practice. JB Lippincott, Philadelphia: 407.

13 Lorder J (1961) Systematic ventriculography studies in infants born with meningomyelocele and encephalocele. The incidence and development of hydrocephalus. Arch Dis Child 36: 381-389.

14 Carmel PW (1977) Spina bifida. In: Downley JA, Low NL, editors. Incapacitating Chronic Diseases in Children. Principles of Rehabilitation. Pediatrica, Barcelona: 159-179. 
15 Park TS, Cail WS, Maggio WM, Mitchell DC (1985) Progressive spasticity and scoliosis in children with myelomeningocele. J Neurosurg 62: 367-375.

16 Shurtleff DB, Godney R, Gordon LH (1976) Myelodisplasia, the natural history of kyphosis and scoliosis: A preliminary report. Dev Med Child Neurol Suppl 37: 126-133. 